\title{
Exercise responses in patients treated for pulmonary tuberculosis by thoracoplasty
}

\author{
M S PHILLIPS, W J M KINNEAR, D SHAW, J M SHNEERSON \\ From the Chest Unit and Department of Respiratory Physiology, Papworth Hospital, Cambridge
}

\begin{abstract}
Twenty eight subjects (mean age 64 years) who had been treated for tuberculosis by thoracoplasty in the past performed an increasing work rate exercise test, from which maximum oxygen consumption ( $\dot{\mathrm{O}}_{2} \mathrm{max}$ ), ventilation and heart rate were measured. $\mathrm{Vo}_{2} \mathrm{max}$ was significantly lower than predicted, being $0.75 \mathrm{l} / \mathrm{min}$ in 17 subjects, $1.01 / \mathrm{min}$ in 10 , and $1.51 / \mathrm{min}$ in one. Only one subject achieved a heart rate of $85 \%$ of the predicted maximum. The ratio of heart rate to oxygen consumption $\left(\mathrm{HR} / \mathrm{Vo}_{2}\right)$ and heart rate at standard interpolated submaximal levels of oxygen uptake at $0.75 \mathrm{l} / \mathrm{min}$ (heart rate 0.75 ) and $1.0 \mathrm{l} / \mathrm{min}$ (heart rate 1.0 ) were normal. Vo $\mathrm{o}_{2}$ max correlated with ventilation at maximal exercise (VE max) $(r=0.87)$ and $\mathrm{FEV}_{1}(\mathrm{r}=0.47)$. It did not correlate with resting arterial oxygen or carbon dioxide tensions, $\mathrm{FEV}_{1}$, maximum inspiratory pressure, angle of scoliosis, or number of ribs resected. The relation between ventilation and oxygen consumption ( $\mathrm{V} E /$ $\left.\dot{\mathrm{V}} \mathrm{O}_{2}\right)$ and $\dot{\mathrm{V}} \mathrm{E}$ at the submaximal levels of oxygen consumption of $0.75 \mathrm{l} / \mathrm{min}(\mathrm{VE} 0.75)$ and $1.01 / \mathrm{min}$ $(\dot{V} E 1 \cdot 0)$ were normal. In 10 subjects a plateau of breathing frequency (fmax) was reached, after which the increase in ventilation was achieved by a further increase in tidal volume (VT). These subjects showed significantly lower values for the forced expiratory ratio, $\dot{\mathrm{V}} \mathrm{o}_{2} \mathrm{max}$, and $\dot{\mathrm{V}} \mathrm{Emax}$ than those with a normal relation between tidal volume and breathing frequency. VEmax was correlated with FEV $(\mathrm{r}=0.61), \mathrm{FVC}(\mathrm{r}=0.46)$, maximum VT $(\mathrm{r}=0.55)$, change in VT $(\mathrm{r}=0.52)$, fmax $(\mathrm{r}=0.56)$, and change in breathing frequency $(\mathrm{r}=0.72)$. These results indicate that exercise in patients treated for tuberculosis by thoracoplasty is limited by ventilatory capacity and that this is due to a reduction in both dynamic lung volumes and respiratory frequency.
\end{abstract}

\section{Introduction}

Many patients who were treated for pulmonary tuberculosis by thoracoplasty now report reduced exercise tolerance. The reasons for this have not been established but several factors may be important. Patients with a thoracoplasty have a restrictive ventilatory defect as a result of the operation. ${ }^{12}$ This worsens with time because of the thoracic scoliosis that is an almost inevitable long term complication. ${ }^{3}$ Airflow obstruction was a common finding in patients with chronic pulmonary tuberculosis during the thoracoplasty era. ${ }^{4}$ Cor pulmonale is a late complication in some patients with a thoracoplasty, ${ }^{5}$ while in others pulmonary hypertension and right ventricular dysfunction limit exercise before peripheral oedema appears.

Address for reprint requests: Dr J M Shneerson, Papworth Hospital, Papworth Everard, Cambridge CB3 8RE.

Accepted 27 January 1989
The respiratory and cardiac responses to exercise may be measured during an increasing work load exercise test with calculation of ventilation and heart rate at standard levels of submaximal oxygen uptake. This test has been used in normal subjects ${ }^{6}$ and in patients with restrictive lung disease, ${ }^{7}$ airflow obstruction, ${ }^{8}$ and scoliosis. ${ }^{9}$ In normal subjects and those with cardiac disease exercise is limited by circulatory factors whereas ventilation usually limits exercise in patients with lung disease ${ }^{78}$ and scoliosis. ${ }^{9}$ We have used an increasing work rate test to ascertain whether abnormalities of ventilation or cardiac function, or both, limit the exercise tolerance of patients treated by thoracoplasty.

\section{Subjects and methods}

We studied 28 subjects ( 18 men, 10 women), whose ages ranged from 51 to 76 (mean 64) years. All had 
previously been treated for pulmonary tuberculosis by thoracoplasty. Three patients had had bilateral operations. All the patients gave informed consent.

The number of ribs resected was determined from a chest radiograph and the angle of scoliosis from a radiograph of the thoracic spine, the method described by Cobb being used. ${ }^{10}$ The partial pressures of oxygen and carbon dioxide were measured in arterial blood $\left(\mathrm{PaO}_{2}\right.$ and $\left.\mathrm{PaCO}_{2}\right)$ drawn with the patient breathing room air at rest (Radiometer, Copenhagen, ABL3). $F_{\text {FV }}$ and forced vital capacity (FVC) were measured with a dry bellows spirometer (Vitalograph). Maximal inspiratory pressure (PImax) was measured at residual volume in 18 subjects.

Exercise was performed on a treadmill (PK Morgan). The subject breathed through a two way valve (Otis-McKerrow), which delivered expired gas through a mixing chamber to a pneumotachograph (Fleisch No 2) connected to a pressure transducer (Validyne MP 45) and amplifier. The flow signal was integrated (PK Morgan respiratory integrator) and, together with the oxygen and carbon dioxide concentrations of the expired gas, derived by mass spectrometry (Centronics $200 \mathrm{MGA}$ ), was recorded continuously on a three channel recorder (Gould 2000S). Minute volume, gas concentrations, and a 12 lead electrocardiogram were recorded at rest and at a single point during a steady state at or after the end of each level of exercise according to the response times of the monitors. Heart rate was recorded continuously throughout. From the results oxygen uptake and carbon dioxide excretion were derived by manual transcription of chart recorder data into an Apple II + computer by the formula

$\mathrm{VO}_{2}(\mathrm{STPD})=\left[\left(\frac{1-\mathrm{FEO}_{2}-\mathrm{FECO}_{2}}{1-\mathrm{FrO}_{2}} \times \mathrm{FiO}_{2}\right)-\mathrm{FEO}_{2}\right] \times \dot{\mathrm{VE}}(\mathrm{STPD}) \times 10^{3} \mathrm{ml}$,

where $\mathrm{FEO}_{2}$ and $\mathrm{FECO}_{2}$ are the fractional concentrations of oxygen and carbon dioxide respectively in expired air and $\mathrm{FIO}_{2}$ the fractional concentration of oxygen in inspired air.

Before exercise baseline measurements were made over three minutes with the patient at rest. The treadmill was started at a speed of $15 \mathrm{~m} / \mathrm{min}(0.9$ $\mathrm{km} / \mathrm{h}$ ), which was increased by $15 \mathrm{~m} / \mathrm{min}$ at one minute intervals. The subjects were encouraged to exercise until compelled to stop by dyspnoea or fatigue, or until a heart rate equal to $85 \%$ of the maximum predicted for their age 11 was reached.

Over the range of exercise achieved, the relation between ventilation and oxygen uptake $\left(\hat{\mathrm{VE}} / \hat{\mathrm{VO}}_{2}\right)$ and between heart rate and oxygen uptake $\left(\mathrm{HR} / \mathrm{VO}_{2}\right)$ was linear. The ventilation and heart rate responses to exercise were expressed as the slope of the relation to $\dot{\mathrm{V}}_{2}\left(\dot{\mathrm{V} E} / \dot{\mathrm{VO}}_{2}, \mathrm{HR} / \dot{\mathrm{VO}}_{2}\right)$, maximum values (VEmax,
HRmax), and interpolated values at an oxygen uptake of $0.751 / \mathrm{min}$ (V் 0.75 , HR 0.75 ), $1.01 / \mathrm{min}$ (VE 1.0 , HR 1.0 ) and $1.5 \mathrm{l} / \mathrm{min}$ (VE 1.5 , HR 1.5 ). The pattern of breathing was assessed as change in tidal volume (VT) and breathing frequency (f) with increasing minute ventilation (VE).

The results were compared with those obtained in normal subjects over the age of $40{ }^{6}$ Analysis was by comparison of means and Spearman's rank correlation test.

\section{Results*}

In the three subjects with bilateral thoracoplasties the upper five ribs had been removed from each side. In the other 25 the number of ribs resected ranged from four to nine (mean 6.6). The Cobb angle ranged from $0^{\circ}$ ( 1 subject) to $61^{\circ}$ (mean $25^{\circ}$ ). The FEV , was less than the mean predicted value ${ }^{12}$ in all 28 subjects; FVC was less than the mean predicted value in 27 . The mean (SD) $\mathrm{FEV}_{\text {, was }} 1.4(0.6) 1$ and mean (SD) FVC 2.0 (0.8) $1 . \mathrm{PaO}_{2}$ ranged from 4.5 to $12.5 \mathrm{kPa}$, with a mean (SD) of $9.7(1.8) \mathrm{kPa} . \mathrm{PaCO}_{2}$ ranged from 4.9 to $8.8 \mathrm{kPa}$ with a mean (SD) of $6.0(0.9) \mathrm{kPa}$. $\mathrm{PaO}_{2}$ correlated with $\mathrm{FEV}_{1}(\mathrm{p}<0.05)$ but not FVC. $\mathrm{PaCO}_{2}$ correlated inversely with $\mathrm{FEV}_{1}(\mathrm{p}<0.001)$ and $\mathrm{FVC}(\mathrm{p}<0.05)$.

During the increasing work rate test the 28 subjects exercised for one to nine (mean 4.7) minutes. One was limited by intermittent claudication and another by a fixed knee joint affected by old tuberculosis. In the other 26 exercise ability appeared to be limited by cardio-respiratory function. Only one patient

*Tables of individual results may be obtained from the authors.
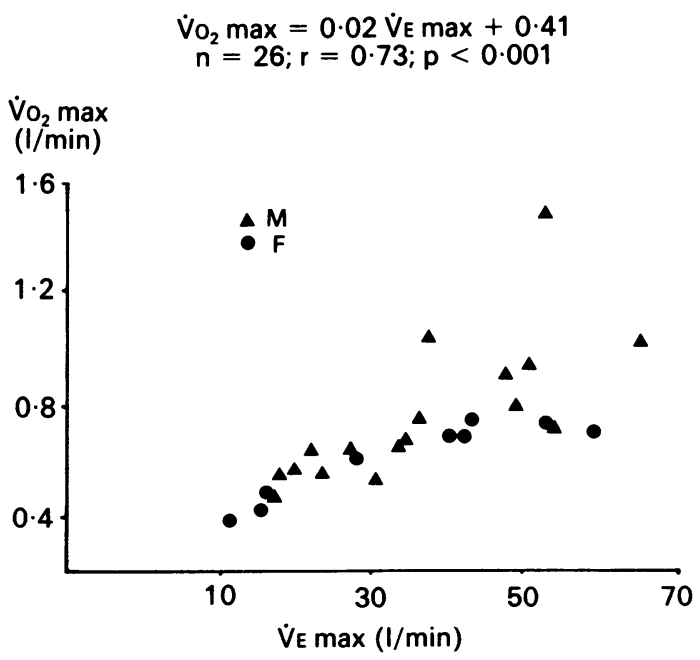

Fig 1 Relation between maximum oxygen consumption $\left(\mathrm{VO}_{2}\right.$ max) and maximum minute ventilation ( $\left.\dot{\mathrm{V}}_{\mathrm{E} \text { max }}\right)$. 

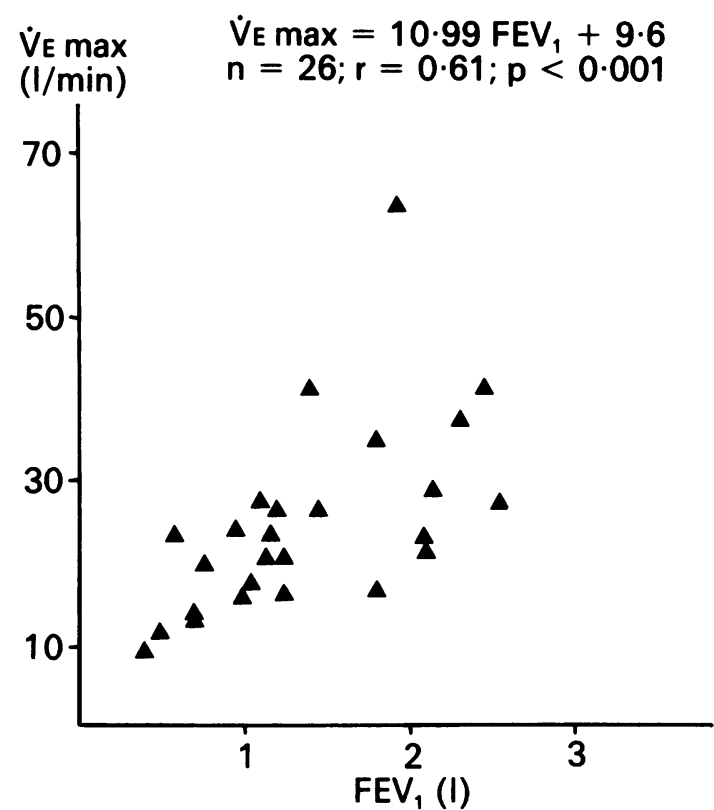

Fig 2 Relation between maximum minute ventilation $\left(V_{\mathrm{E}} \max \right)$ and $F E V_{1}$.

achieved a heart rate of $85 \%$ of the maximum predicted for her age. This was achieved after only two minutes of exercise and coincided with maximum exertion, limited by dyspnoea. Nineteen of the other 25 subjects stopped exercising because of dyspnoea, four were limited by fatigue and two by dizziness.

\section{MAXIMUM OXYGEN UPTAKE}

$\dot{\mathrm{V}} \mathrm{O}_{2} \max$ ranged from 6.8 to $23.1 \mathrm{ml} / \mathrm{min} / \mathrm{kg}$ body weight (mean (SD) $14.3(4 \cdot 3)$ ), and was less than expected from the predicted values of $B$ ruce $^{13}$ in all except one subject. Seventeen subjects exercised to an oxygen consumption of $0.75 \mathrm{1} / \mathrm{min}, 10$ reached 1.0 $1 / \mathrm{min}$, but only one achieved $1.5 \mathrm{l} / \mathrm{min}$. Vo ${ }_{2}$ correlated with VEmax $(r=0.73, p<0.001), F_{1} V_{1}(r=0.53$, $p<0.01)$, and to a lesser extent FVC $(r=0.43$,

Table 1 Response of ventilation to exercise (mean (SD) values)

\begin{tabular}{|c|c|c|c|c|}
\hline Index & Sex & $n$ & Patients & $\begin{array}{l}\text { Normal } \\
\text { subjects }^{6}\end{array}$ \\
\hline$\dot{\mathrm{V}} \mathrm{E}$ rest $(\mathrm{l} / \mathrm{min})$ & $\begin{array}{l}\mathbf{M} \\
\mathbf{F}\end{array}$ & $\begin{array}{l}18 \\
10\end{array}$ & $\begin{array}{r}10.0(0.6) \\
7.8(0.6)\end{array}$ & \\
\hline $\begin{array}{l}\text { Slope } \dot{V E} / \dot{V}_{2} \\
(1 / 1) \\
\dot{V} E_{0.75}(1 / \mathrm{min})\end{array}$ & $\begin{array}{l}\mathbf{M} \\
\mathbf{F} \\
\mathbf{M}\end{array}$ & $\begin{array}{l}18 \\
10 \\
11\end{array}$ & $\begin{array}{l}26.4(8.5) \\
24.6(4 \cdot 7) \\
19 \cdot 5(3.6)\end{array}$ & $\begin{array}{l}23 \cdot 2(10 \cdot 3) \\
27 \cdot 1 \quad(7 \cdot 8) \\
18 \cdot 7 \quad(4 \cdot 5)\end{array}$ \\
\hline$\dot{\mathrm{V}} \mathrm{E}_{1 \cdot 0}(\mathrm{l} / \mathrm{min})$ & $\begin{array}{l}\mathbf{F} \\
\mathbf{M} \\
\mathbf{F}\end{array}$ & $\begin{array}{l}6 \\
6 \\
4\end{array}$ & $\begin{array}{l}16.8(2.9) \\
27.5(7.8) \\
21.4(3.6)\end{array}$ & $\begin{array}{ll}21.2 & (2.4)^{* * *} \\
25.0 & (4.5) \\
27.0 & (2 \cdot 7)^{* *}\end{array}$ \\
\hline
\end{tabular}

$* * \mathrm{p}<0.01$.

$\dot{\mathrm{V}} \mathrm{E}$-minute ventilation; $\mathrm{V}_{2}$-oxygen uptake.

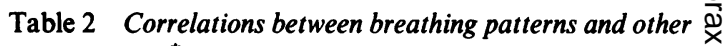
measurements*

\begin{tabular}{|c|c|c|c|c|}
\hline & $\begin{array}{l}V \mathrm{~T} \max \\
\text { (l) }\end{array}$ & $\begin{array}{l}V \mathrm{~T} \\
(l)\end{array}$ & $\underset{\text { (breaths/min) }}{\text { fmax }}$ & $f_{\text {(breaths/min) }}$ \\
\hline $\begin{array}{l}\mathrm{FEV}_{1}(1) \\
\text { FVC (1) } \\
\text { FER (\%) } \\
\mathrm{PaO}_{2}(\mathrm{kPa}) \\
\mathrm{PaCO}_{2}(\mathrm{kPa}) \\
\mathrm{VEmax}_{(1 / \mathrm{min})}\end{array}$ & $\begin{array}{r}0.78 \\
0.71 \\
0.40 \\
0.53 \\
-0.60 \\
0.78\end{array}$ & $\begin{array}{r}0.73 \\
0.59 \\
0.49 \\
0.51 \\
-0.59 \\
0.73\end{array}$ & $\begin{array}{r}-0.33 \\
-0.42 \\
0.03 \\
-0.42 \\
-0.18 \\
0.16\end{array}$ & $\begin{array}{r}-0.24 \\
-0.39 \\
0.15 \\
-0.06 \\
-0.14 \\
0.40\end{array}$ \\
\hline $\begin{array}{l}\text { Pimax } \\
(\mathrm{mm} \mathrm{Hg})\end{array}$ & 0.41 & 0.48 & 0.01 & 0.37 \\
\hline
\end{tabular}

*See text.

FVC - forced vital capacity; FER - forced expiratory ratio; $\mathrm{PaO}_{2}-\overrightarrow{\mathrm{x}}$ arterial oxygen tension; $\mathrm{PaCO}_{2}-$ arterial carbon dioxide tension;

Vemax-maximum minute ventilation; Pimax-maximum inspiratory pressure; $\mathrm{f}$ - breathing frequency; $\mathrm{VT}$ - tidal volume.

$\mathrm{p}<0.05)$. The relation between $\dot{\mathrm{V}} \mathrm{O}_{2} \max$ and $\dot{\mathrm{V}} \mathrm{Emax}$ iᄋ illustrated in figure 1.

\section{MAXIMUM VENTILATION}

VEmax ranged from 9.0 to $63.5 \mathrm{l} / \mathrm{min}$ (mean (SD) $24 \cdot \overrightarrow{\mathrm{ko}}$ (11.6)). It correlated with $\mathrm{FEV}_{1}(\mathrm{r}=0.61, \mathrm{p}<0.01)$ to a lesser extent with FVC $(r=0.55, p<0.01)$, but not with PImax $(r=0.44$, NS). The relation between VEmax and FEV , is illustrated in figure 2.

\section{MINUTE VENTILATION DURING EXERCISE}

The response of $\dot{V}_{E}$ during exercise is shown in table 1

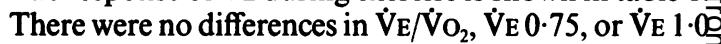

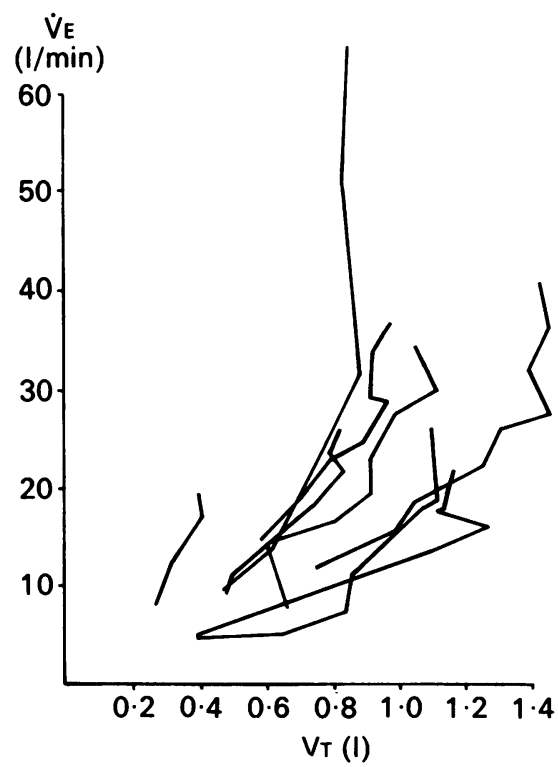

Fig 3 Relation between minute ventilation (VE) and tidal volume (VT) (Hey plot) in eight patients with a normal breathing pattern. 


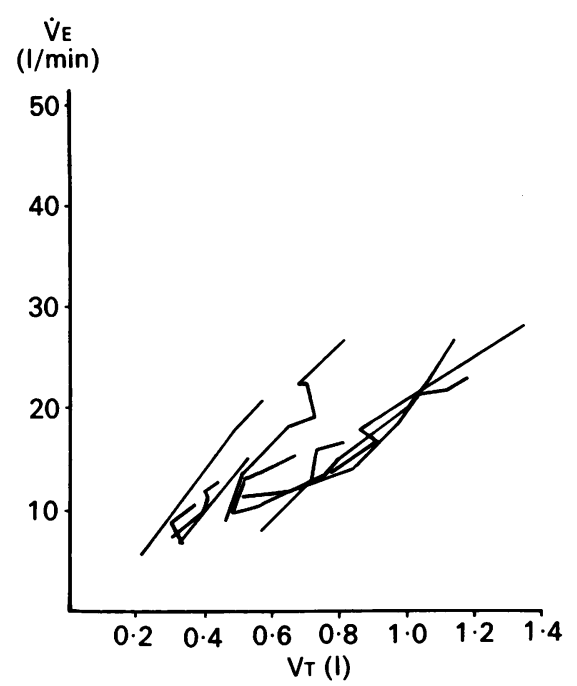

Fig 4 Relation between minute ventilation $\left(V_{\mathrm{E}}\right)$ and tidal volume (VT) (Hey plot) in 10 patients showing a plateau of breathing frequency.

between the sexes. For the men all values were within 1 $\mathrm{SD}$ of the mean value obtained by Spiro et al in normal men over the age of $40 .^{6}$ For the women $\dot{\mathrm{VE}} / \mathrm{VO}_{2}$ was

$$
\underset{(I / \mathrm{min})}{\dot{\mathrm{V}}_{\mathrm{E}}}
$$

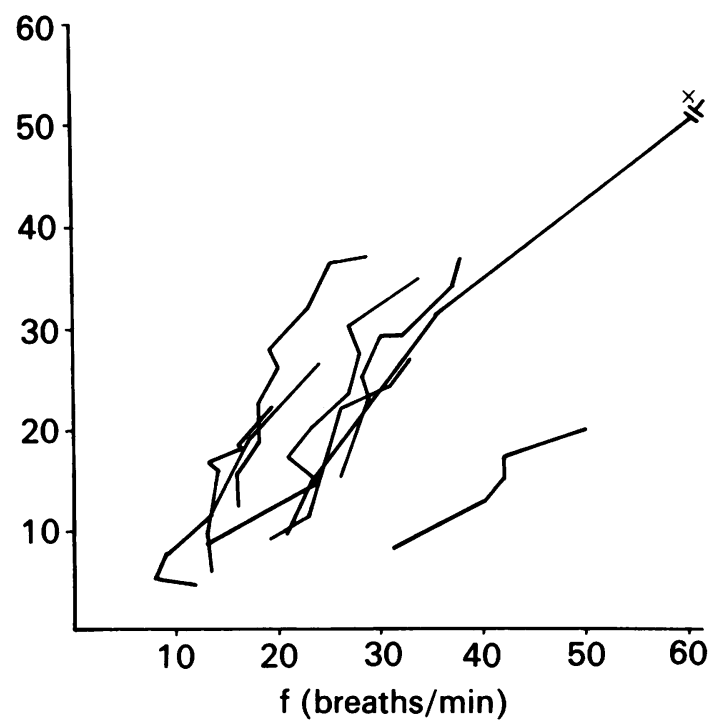

Fig 5 Relation between minute ventilation $\left(\dot{V}_{\mathrm{E}}\right)$ and breathing frequency $(f)$ in eight patients with a normal breathing pattern. $X$-one subject at maximum exercise: $\dot{V} \mathrm{E}=63.5 \mathrm{l} / \mathrm{min} ; f=76$ beats $/ \mathrm{min}$.

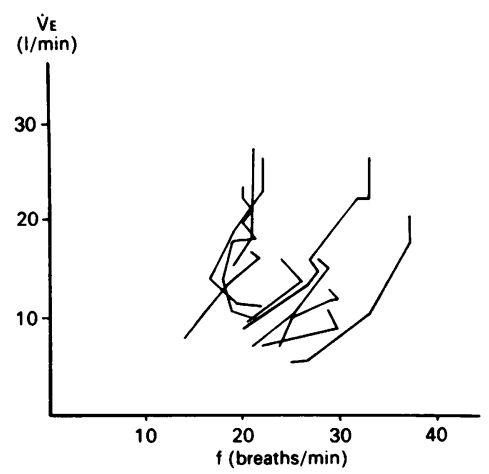

Fig 6 Relation between minute ventilation $(V \mathrm{E})$ and breathing frequency $(f)$ in 10 patients who showed a plateau of breathing frequency.

similar to the value obtained in normal women but $\dot{V} E$ 0.75 and VE 1.0 were lower than expected.

\section{RELATION OF OXYGEN UPTAKE AND}

VENTILATION TO OTHER FACTORS

There were no significant correlations, either for the group as a whole or for either sex, between $\dot{V}_{2} \max$, VEmax, $\dot{V} E / \dot{V}_{2}, \dot{V} E \mathbf{0} \cdot 75$, or $\dot{V} E 1.0$ and the number of ribs resected, the angle of scoliosis, $\mathrm{PaO}_{2}$, or $\mathrm{PaCO}_{2}$. $\dot{V}_{2}$ max was correlated with PImax (Spearman's rho $(\rho)=0.43, \quad \mathrm{p}<0.05)$ and VEmax $(\rho=0.47$, $\mathrm{p}<0.05)$.

\section{PATTERN OF BREATHING}

At rest the typical breathing pattern was a low tidal volume (VT) and high breathing frequency (f). The mean (SD) values for $\mathrm{VT}$ and $\mathrm{f}$ at rest were $0.46(0 \cdot 14) 1$ and $20.9(4.8)$ breaths $/ \mathrm{min}$. There were significant correlations (table 2) between both maximum tidal volume (VTmax) and the change in tidal volume from

Table 3 Respiratory data (mean (SD) values) for those with a normal breathing pattern during exercise and those

\begin{tabular}{|c|c|c|}
\hline Index & $\begin{array}{l}\text { Normal breathing } \\
\text { pattern }(n=8)\end{array}$ & $\begin{array}{l}\text { Plateau of breathing } \\
\text { frequency }(n=10)\end{array}$ \\
\hline $\begin{array}{l}\Delta f(\text { breaths } / \mathrm{min}) \\
\dot{\operatorname{Vo}} \max (1 / \mathrm{min}) \\
\operatorname{VEmax}_{(1 / \mathrm{min})} \\
\text { FEV }(1) \\
\text { FVC (l) } \\
\text { FER \% } \\
\Delta V \mathrm{VT}(1) \\
\text { VTmax (l) } \\
\text { fmax (breaths/min) }\end{array}$ & $\begin{array}{cl}18.75 & (15.3) \\
1.13 & (0.27) \\
35.6 & (14) \\
1.8 & (0.6) \\
2.4 & (0.9) \\
74.1 & (8.8) \\
0.50 & (0.22) \\
0.97 & (0.30) \\
37.6 & (18.1)\end{array}$ & $\begin{array}{cl}6.5 & (4.2)^{*} \\
0.76 & (0.24)^{* *} \\
20.1 & (6.2)^{*} \\
1.4 & (0.7) \mathrm{NS} \\
2.2 & (0.9) \mathrm{NS} \\
62.9 & (11.8)^{*} \\
0.35 & (0.22) \mathrm{NS} \\
0.79 & (0.33) \mathrm{NS} \\
27.4 & (5.3) \mathrm{NS}\end{array}$ \\
\hline
\end{tabular}
who showed a plateau of breathing frequency

$* \mathrm{p}<0.05 ; * * \mathrm{p}<0.01$.

$\Delta \mathrm{f}$-change in breathing frequency; $\Delta \mathrm{V}_{\mathrm{T}}$ - change in tidal volume; fmax-maximum breathing frequency; VTmax-maximum tidal volume. Other abbreviations as in tables 1 and 2 . 
Table 4 Response of heart rate (HR) during exercise (mean (SD) values)

\begin{tabular}{|c|c|c|c|c|}
\hline Index & Sex & $n$ & Patients & $\begin{array}{l}\text { Normal } \\
\text { subjects }^{6}\end{array}$ \\
\hline $\begin{array}{c}\text { Slope } \mathrm{HR} / \mathrm{VO}_{2} \\
\text { (beats/l) } \\
\mathrm{HR} \text { rest } \\
\text { (beats/min) } \\
\mathrm{HR}_{0.75} \\
\quad(\text { beats } / \mathrm{min} \text { ) } \\
\mathrm{HR}_{1.0} \\
\text { (beats } / \mathrm{min})\end{array}$ & $\begin{array}{l}\mathbf{M} \\
\mathbf{F} \\
\mathbf{M} \\
\mathbf{F} \\
\mathbf{M} \\
\mathbf{F} \\
\mathbf{M} \\
\mathbf{F}\end{array}$ & $\begin{array}{r}18 \\
10 \\
18 \\
10 \\
11 \\
6 \\
6 \\
4\end{array}$ & $\begin{array}{r}46 \cdot 5(23.8) \\
80.4(58.8) \\
83 \cdot 1(12 \cdot 7) \\
110 \cdot 3(12.3) \\
96.9(12.3) \\
106 \cdot 3(12.2) \\
100 \cdot 7(15.4) \\
116.0(18.8)\end{array}$ & $\begin{array}{r}95.0(13.9) \\
117.4(16.8) \\
105.6(13.9) \\
136.9(21.3)\end{array}$ \\
\hline
\end{tabular}

$\mathrm{V}_{2}-$ oxygen consumption.

rest to maximum exercise $(\Delta V T)$ and FEV $_{1}$, FVC, forced expiratory ratio (FER), $\mathrm{PaO}_{2}$, and $\mathrm{PaCO}_{2}$. There were no significant correlations between either maximum breathing frequency (fmax) or change in breathing frequency from rest to maximum exercise $(\Delta f)$ and any of these indices or PImax. VEmax showed a significant correlation with VTmax, VT, fmax, and $\mathrm{f}$.

Analysis of the response in individual subjects showed no change in VT in two, the small increase in ventilation observed being due to an increase in breathing frequency. These two subjects reached maximum exercise after only one and two minutes respectively. In the other 24 subjects whose exercise was limited by cardiorespiratory function VT increased linearly, at least during the early stages of exercise. In eight subjects a maximum tidal volume that was lower than normal was reached before the limit of exercise; a further rise in minute ventilation then occurred through an increase in breathing frequency. This is the normal pattern of breathing response to exercise described by Hey et $a l^{14}$ and Kelman and Watson. ${ }^{15}$ The Hey plot (minute ventilation against VT) for these eight subjects is shown in figure 3. In a further six subjects VT and $f$ were both increasing when VEmax was reached. This pattern may also be seen in normal people, but is less common. ${ }^{14}$ is The other 10 subjects showed an unusual pattern of breathing in response to exercise. They reached their maximum breathing frequency (fmax) before the last work load, and a further increase in minute ventilation was then achieved by a further rise in VT, with no inflexion point on the Hey plot (fig 4). The influence of a maximum limit in breathing frequency on ventilation in these 10 patients is shown in figures 5 and 6 . When these 10 subjects were compared with the eight with the normal breathing pattern (table 3), they showed significantly lower values of $\mathrm{f}, \mathrm{V}_{2} \max$, VEmax. PImax, and FER. Their values for FEV FVC, VT, VTmax, and fmax were lower but the differences were not significant. There were no differences in age, resting $\mathrm{PaO}_{2}, \mathrm{PaCO}_{2}$, tidal volume, or breathing frequency at rest between the two groups.
HEART RATE

At maximum exercise the heart rate for men ranged: from 67 to 140 beats/min (mean (SD) 110.3 (18.5)) and for women from 92 to 150 beats/min (123.6 (19.9))?응 The heart rate responses to exercise are shown in table음 4. $\mathrm{HR} / \mathrm{Vo}_{2}, \mathrm{HR} 0.75$, and $\mathrm{HR} 1.0$ are, as expected $\overline{\bar{N}}$ greater in women than in men. The values for each index do not differ significantly from the valueso obtained by Spiro et al ${ }^{6}$ in normal subjects.

\section{Discussion}

These results confirm that patients treated for pulmon $-\underset{x}{\vec{x}}$ ary tuberculosis by thoracoplasty have a reduced exercise tolerance. They show that the exercises tolerance of individual patients cannot be predictedi from resting arterial blood gas analysis, number of ribs resected, or the angle of scoliosis. Our subjects showed? a more limited exercise tolerance than the patients with fibrosing alveolitis, ${ }^{7}$ chronic bronchitis, ${ }^{8}$ and scoliosis $^{9}$ who have been studied in this way.

In normal subjects the limit to exercise is imposed by $\overrightarrow{0}$ the circulation. A heart rate of $85 \%$ of the predictedo maximum was observed in only one of our subjects ait maximum exercise and interpolated submaxima? indices for heart rate and $\mathrm{HR} / \mathrm{VO}_{2}$ were normal. This contrasts with patients with restrictive lung disease $\mathrm{e}^{710}$ and obstructive bronchitis, ${ }^{8}$ in whom these sub-市 maximal indices are increased to compensate for the abnormally low stroke volume, which may resultê, either from a reduction in right heart filling pressure ${ }^{16}$ or from left ventricular disease. ${ }^{17}$ In our subjects the normal values of $\mathrm{HR} / \mathrm{VO}_{2}, \mathrm{HR} 0.75$, and $\mathrm{HR} 1.0$. suggest that the stroke volume response is not abnor mal and that the circulation does not limit exercise.

The correlations between $\dot{V}_{2} \max$ and the three indices of ventilatory capacity, VEmax, $\mathrm{FEV}_{1}$, and FVC, indicate that it was the reduction in ventilatoryo capacity that limited exercise. Such correlations are not found in normal subjects but they have been noted 0 in patients with lung disease ${ }^{78}$ and scoliosis, ${ }^{9}$ in whom? exercise is usually limited by ventilation. In patient with interstitial lung disease Burdon et $a l^{18}$ found that maximum exercise correlated with FVC. In chronico airflow obstruction most investigators have found that maximum exercise correlates with FEV, when bicycle ergometry ${ }^{820}$ but not 12 minute walking distance is used as the index of exercise. . $^{20-22}$

In our subjects the measurements of ventilatory response to submaximal exercise did not show the importance of decreased ventilatory capacity in limit ing exercise. Minute ventilation was reported at interpolated values of $\dot{\mathrm{VO}}_{2}$ such as 1.01 . These valuesक reflect both the intercept of ventilation on the $\mathrm{V}_{2}$ axis? and the slope of the ventilatory response. The relation of ventilation to oxygen uptake $\left(\dot{\mathrm{VE}} / \mathrm{Vo}_{2}\right)$ was normal: 
A normal $\dot{\mathrm{VE}} / \dot{\mathrm{V}}_{2}$ relationship may, however, conceal a high $\mathrm{VD} / \mathrm{VT}$ in conjunction with a rising $\mathrm{PCO}_{2}$ during exercise. Such a relationship has been found in patients with scoliosis ${ }^{9}$ and in patients with obstructive bronchitis with an $\mathrm{FEV}_{1}$ of less than 1.0 litre, ${ }^{8}$ in both of whom exercise is limited by ventilation. In our series the values of minute ventilation at submaximal levels of exercise were normal in the 11 men who were able to exercise to an oxygen consumption of $0.75 \mathrm{l} / \mathrm{min}$. This differs from results obtained from the patients with scoliosis and severe obstructive bronchitis, where minute volumes at submaximal levels of exercise were greater than normal. ${ }^{7-9}$ The lower than normal values of $\dot{V}_{E} 0.75$ and $\dot{V}_{E} 1.0$ seen in our female subjects is unexplained but the numbers of subjects (six and four respectively) were small.

In normal subjects breathing frequency remains constant at the start of exercise while tidal volume increases. Later both tidal volume and breathing frequency increase. In most a plateau of tidal volume is reached and the final increase in ventilation is through a further rise in breathing frequency. ${ }^{14}{ }^{15}$ Patients with restrictive lung diseases typically respond to exercise by breathing with a low tidal volume and a rapidly increasing breathing frequency. ${ }^{1823}$ This pattern of breathing minimises the work of breathing in the presence of decreased lung compliance. ${ }^{24}$ Patients with airflow obstruction might be expected to respond to exercise with a large tidal volume and decreased breathing frequency, ${ }^{25}$ but they also increase breathing frequency during exercise. ${ }^{26}$ Garrard and Lane suggested that in patients with airflow obstruction subjected to carbon dioxide induced hyperpnoea this pattern of response may be explained by the "restrictive defect" imposed by the decrease in chest wall compliance associated with hyperinflation. ${ }^{27}$ Patients with airflow obstruction are unable to increase breathing frequency to the same degree as those with restrictive lung disease, however, because of the characteristic reduction in expiratory flow rates. ${ }^{2628}$ Though there was no correlation between FER and maximum breathing frequency for the group as a whole our 10 subjects with a low maximum breathing frequency had significantly lower values of FER than those with a normal breathing pattern, and they achieved significantly lower levels of $\dot{V}_{2}$ max and $\dot{V}$ Emax. The results suggest that airflow obstruction limits exercise tolerance in patients with an underlying restrictive defect by preventing an increase in breathing frequency.

This study has therefore confirmed that patients treated for pulmonary tuberculosis by thoracoplasty have a reduced exercise tolerance. The low values of VEmax and the correlation between $\dot{V}_{2} \max$ and VEmax, $F_{E V}$, and FVC indicate that exercise is limited by the decreased ventilatory capacity. FEV correlated more strongly with both $\mathrm{Vo}_{2} \max$ and
VEmax than did FVC, unlike in restrictive lung disease $^{7}$ and scoliosis, ${ }^{9}$ where the strongest correlation is with FVC. The pattern is similar to that seen in obstructive bronchitis, ${ }^{819} \mathrm{emphasising} \mathrm{the} \mathrm{importance}$ of airflow obstruction. An unusually low maximum breathing frequency during exercise was associated with greater airflow obstruction and with lower values of $\dot{\mathrm{V}}_{2} \max$ and $\dot{\mathrm{V}} \mathrm{Emax}$.

We thank Drs J E Stark and T W Higenbottam for allowing us to study their patients and Miss Jane Whiting, Miss Sally Smyth, Miss Julie Harris, and Mrs Kath Sharratt for typing the manuscript.

\section{References}

1 Cournand A, Richards DW. Pulmonary insufficiency II. The effects of various types of collapse therapy on cardiopulmonary function. Am Rev Tuberc 1941; 44:123-72.

2 Landis FB, Weisel W. Comparative study of pulmonary function loss: thoracoplasty versus small resection in surgery of tuberculosis. J Thorac Surg 1954;27:336-48.

3 Loynes RD. Scoliosis after thoracoplasty. J Bone Joint Surg 1972;54B:484-98.

4 Lancaster JF, Tomashefski JF. Tuberculosis-a cause of emphysema. Am Rev Respir Dis 1963;87:435-7.

5 Zimmerman HA. Hemodynamics: studies on a group of patients who developed cor pulmonale following thoracoplasty. J Thorac Surg 1951;22:94-8.

6 Spiro SG, Juniper E, Bowman P, Edwards RHT. An increasing workrate test for assessing the physiological strain of sub-maximal exercise. Clin Sci 1974;46: 191-206.

7 Spiro SG, Dowdeswell IRG, Clark TJH. An analysis of sub-maximal exercise responses in patients with sarcoidosis and fibrosing alveolitis. $\mathrm{Br} J$ Dis Chest 1981;75:169-80.

8 Spiro SG, Hahn HL, Edwards RHT, Pride NB. An analysis of the physiological strain of exercise in patients with chronic obstructive bronchitis. Thorax 1975;30:415-25.

9 Shneerson JM. The cardiorespiratory response to exercise in thoracic scoliosis. Thorax 1978;33:457-63.

10 Cobb JR. Outline for the study of scoliosis. Ann Arbor: American Academy of Orthopaedic Surgeons, 1948;5:261-75. (Instructional course lectures.)

11 Astrand I. Aerobic work capacity in men and women with special reference to age. Acta Physiol Scand 1960;49(suppl):169.

12 Quanjer P. Standardised lung function testing. Bull Eur Physiopathol Respir 1983;19(suppl 5):1-95.

13 Bruce RA, Kusumi F, Hosmer D. Maximal oxygen intake and nomographic assessment of functional aerobic impairment in cardiovascular disease. $\mathrm{Am}$ Heart J 1973;85:546-64.

14 Hey EN, Lloyd BB, Cunningham DJC, Jukes MGM, Bolton DPG. Effects of various respiratory stimuli on the depth and frequency of breathing in man. Respir Physiol 1966;1:193-205. 
15 Kelman GR, Watson AWS. Effect of added respiratory dead-space on the "Hey Plot." J Physiol (Lond) 1972;227:47-9P.

16 Gabriel SK. Respiratory and circulatory investigations in obstructive and restrictive lung diseases. Acta Med Scand 1973;suppl 546:49-72.

17 Baum GL, Schwartz A, Llamas R, Castillo C. Left ventricular function in chronic obstructive lung disease. $N$ Engl J Med 1971;285:361-5.

18 Burdon JGW, Killian KJ, Jones NL. Pattern of breathing during exercise in patients with interstitial lung disease. Thorax 1983;38:778-84.

19 Jones NL, Jones G, Edwards RHT. Exercise tolerance in chronic airway obstruction. Am Rev Respir Dis 1971;103:477-91.

20 McGavin CR, Gupta SP, McHardy GJR. Twelve minute walking test for assessing disability in chronic bronchitis. Br Med J 1976;i:822-3.

21 Mungall IPF, Hainsworth R. Assessment of respiratory function in patients with chronic obstructive airways disease. Thorax 1979;34:254-8.

22 Swinburn CR, Wakefield JM, Jones PW. Performance, ventilation and oxygen consumption in three different types of exercise test in patients with chronic obstructive lung disease. Thorax 1985;40:581-6.

23 West JR, Alexander JK. Studies on respiratory mechanics and the work of breathing in pulmonary fibrosis. Am J Med 1959;27:529-44.

24 Jones NL, Rebuck AS. Tidal volume during exercise in patients with diffuse fibrosing alveolitis. Bull Eur Physiopathol Respir 1979;15:321-7.

25 Mcllroy MD, Eldridge RL, Thomas JP, Christie RV. The effect of added elastic and non-elastic resistance on the pattern of breathing in normal subjects. Clin $\mathrm{Sci}$ 1956;15:337-44.

26 Potter WA, Olafsson S, Hyatt RE. Ventilatory mechanics and expiratory flow limitation during exercise in patients with obstructive lung disease. J Clin Invest 1970;50:910-9.

27 Garrard CS, Lane DJ. Pattern of carbon dioxide stimulated breathing in patients with chronic airflow obstruction. Thorax 1981;36:130-4.

28 Morris MJ, Lane DJ. Tidal expiratory flow patterns in airflow obstruction. Thorax 1981;36:135-42. 